\title{
Early warning research of China's vegetable unmarketable based on BP
}

\section{neural network}

\author{
LiJie Sun ${ }^{1}$, Ling $\mathrm{Li}^{1}$, XiaoBo $\mathrm{Gu}^{3}$, XiaoLin Song ${ }^{1}$ and Bo $\mathrm{Lu}^{1,2, \mathrm{a}}$ * \\ ${ }^{1}$ College of Economy and Management, Dalian University, Dalian, China, 116622 \\ ${ }^{2}$ School of Management, Chinese Academy of Sciences, Beijing, China, 100190 \\ ${ }^{3}$ College of City and Environment, Jiangsu Normal University, Xuzhou, China, 221116 \\ aEmail: lubo_documents@hotmail.com
}

Keywords: Vegetables unsalable; BP artificial neural network; Early-warning indicators; Early-warning model; Model training

\begin{abstract}
Vegetables unmarketable in the current economic and social problems often encountered, to know whether there will be vegetables unsalable phenomenon in the future, we have to do early warning research about it. BP artificial neural network has better fuzzy recognition capacity and fault tolerance capacity, becoming the first choice of vegetables unmarketable early-warning model.Thisstudyselects 18 warning signs of indicators, selecting the price volatility as the warning intelligence indicators, constructing early warning indicator system of vegetables unsalable in China .We establish the early-warning models of vegetables unsalable based on BP artificial neural network, carry on the model training with cabbage statistical date of 2000-2009 in Shandong province, and validate the model with the date of 2010-2012. Establishment of early warning models of vegetables unmarketable further demonstrates BP artificial neural network is a more reliable prediction method, which should have better prospects in the application of vegetable unmarketable warning.
\end{abstract}

\section{Research background and Introduction}

The current vegetable market oversupply phenomenon is commonly, andsurplus and shortage appear interactively.This has influenced the stability of the agriculture and the interests of farmers. To reduce the losses caused by vegetable unmarketable, we introduce the early warning model of unsalable vegetables. Current in vegetable unmarketable though haven't early warning research, there have been many scholars apply warning to other agriculture field, such as China's food security[1], regional food security [2], and live pig market monitoring[3].

Economic early warning model is generally divided into econometric model and neural network model. Econometric model needs to establish a clear measurement relationship between variables. However the sellingprocess of vegetables is very complex, so econometric early warning model is difficult to meet the requirements. BP neural network has a good ability of pattern recognition, fault tolerance and relatively loose data distribution requirement. It also can implicitly abstract the interaction and relationships between various factors, make reasonable decision in anuncertain, approximate, even conflicting knowledge environment ${ }^{[4]}$. Therefore, in the vegetable unmarketable early warning using BP artificial neural network model can obtain better effect than other early warning model. 


\section{The vegetable unmarketable early warning model based on BP artificial neural network-a case study of Shandong cabbages}

Table 1Premonition Indexes of early-warning in Shandong

\begin{tabular}{|c|c|}
\hline Group & Early-warning index \\
\hline Supply & $\begin{array}{c}\text { Production rate of change of Chinese } \\
\text { cabbage } V_{1}^{[5]} \\
\text { Planting area rate of growth of Chinese } \\
\text { cabbage } V_{2} \\
\text { Production price rate of change of the } \\
\text { previous period } V_{3}^{[6]} \\
\text { Price Rate of change agricultural means of } \\
\text { production } V_{4}^{[7]}\end{array}$ \\
\hline Demand & $\begin{array}{l}\text { Growth rate of Shandong's rural population } \\
\qquad V_{6} \\
\text { Rate of change of Shandong's urban per } \\
\text { capita disposable income } V_{7} \\
\text { Shandong's rural per capita net income of } \\
\text { growth } V_{8} \\
\text { National rural population growth rate } V_{9} \\
\text { National urban per capita disposable income }\end{array}$ \\
\hline $\begin{array}{l}\text { Environment } \\
\text { of supply } \\
\text { and demand }\end{array}$ & $\begin{array}{c}\text { Freight rate of change } V_{12}{ }^{[8]} \\
\text { Cargo transportation turnover rate of } \\
\text { change } V_{13} \\
\text { Inflation rate } V_{14}{ }^{[9]}\end{array}$ \\
\hline
\end{tabular}

Production ofcabbage accounts for about $16 \%$ of Shandong vegetable production, but its price is extremely unstable. Although its cabbage harvest in 2002, a large number of cabbage couldn't sell, its pricedroppedby $17 \%$.In2006, most of the market of cabbage in Shandong suffered a trough never seen in recent years, its prices as low as $0.12 / \mathrm{kg}$, but still not many people buy. Shandong cabbage harvest in 2008, but the price is diving, some places even sell 0.01/kg. Central news report in 2012 a bag of Chinese cabbage can only change two baked wheat cake. From these examples we can know, Shandong cabbage price is very unstable and often appears unsalable phenomenon. So we chose it as the study object of early warning unmarketable vegetables.

When building early warning model, we must first determine the number of input nodes, and theinput indicator is warning sign index. The warning signs are showninTable1.Second, determine the output nodes.We assumed the output [-1] expresses serious unmarketable, [-0.5] shows the general unsalable, [0] indicates no unmarketable, [0.5]says negative reverse general unmarketable and [1] expresses reverse highly unsalable, the output node number should be 1 .We need to select the reasonable output index as the representative of the degree of unsalable, and we choose the price volatility(PV) as alarm index and the desired output values corresponding to PV of each group are as follows: when $\mathrm{PV}<-10 \%$, output is -1 ; when $-10 \%<\mathrm{PV}<-5 \%$, output is -0.5 ; when $-5 \%<\mathrm{PV}<5 \%$, output is 0 ; when $5 \%<\mathrm{PV}<10 \%$, output is 0.5 ; When $\mathrm{PV}>10 \%$, output is 1 .Finally, determine the number of hidden layer nodes, we can use $\mathrm{k}=(\mathrm{m}+\mathrm{n}) / 2$ ork $=(\mathrm{m}-\mathrm{n}) / 2[10]$ to determine, wheren is the number of input nodes, $\mathrm{m}$ is output nodes, $\mathrm{a}$ is an integer between 1-10. 
After determining the network structure of warning model, we need to use the sample data train after a certain amount learning of the rules and improve the adaptability of the network [11]. We use Shandong cabbage annual data 2000-2009 as sample and establish early warning model for training, use annual data of 2010-2012 test the early-warning model. We can get all data from China Statistical Yearbook, China Rural Statistical Yearbook and Shandong Statistical Yearbook, so here we will only list part of the indicator data in Table 2 and Table 3.

Table 2Sample data of premonition indexes in Shandong cabbage

\begin{tabular}{|l|l|l|l|l|l|l|l|l|l|}
\hline Year & $\mathrm{V}_{1}$ & \multicolumn{1}{|c|}{$\mathrm{V}_{3}$} & \multicolumn{1}{|c|}{$\mathrm{V}_{5}$} & \multicolumn{1}{|c|}{$\mathrm{V}_{7}$} & $\mathrm{~V}_{9}$ & $\mathrm{~V}_{11}$ & $\mathrm{~V}_{12}$ & $\mathrm{~V}_{13}$ & $\mathrm{~V}_{14}$ \\
\hline 2000 & 0.212 & 0.129 & 0.032 & 0.117 & -0.015 & 0.019 & 0.153 & 2.178 & 0.004 \\
\hline 2001 & -0.054 & -0.094 & 0.077 & 0.094 & -0.016 & 0.050 & 0.075 & 0.159 & 0.007 \\
\hline 2002 & 0.104 & 0.335 & -0.150 & 0.145 & -0.070 & 0.046 & 0.080 & -0.35 & -0.008 \\
\hline 2003 & -0.013 & -0.142 & 0.107 & 0.107 & -0.018 & 0.059 & 0.095 & 0.128 & 0.012 \\
\hline 2004 & 0.060 & 0.455 & 0.061 & 0.124 & -0.015 & 0.120 & 0.102 & 0.388 & 0.039 \\
\hline 2005 & -0.086 & -0.020 & 0.213 & 0.138 & -0.015 & 0.108 & 0.121 & 0.167 & 0.018 \\
\hline 2006 & -0.043 & 0.208 & 0.053 & 0.135 & -0.019 & 0.102 & 0.130 & 0.142 & 0.015 \\
\hline 2007 & 0.063 & -0.053 & 0.093 & 0.170 & -0.023 & 0.154 & 0.187 & 0.113 & 0.048 \\
\hline 2008 & 0.043 & 0.342 & 0.070 & 0.143 & -0.015 & 0.150 & 0.188 & 0.316 & 0.059 \\
\hline 2009 & -0.012 & -0.107 & 0.108 & 0.092 & -0.021 & 0.082 & 0.164 & 0.091 & -0.007 \\
\hline 2010 & -0.14 & 0.084 & 0.386 & 0.12 & -0.026 & 0.149 & 0.057 & 0.072 & 0.033 \\
\hline 2011 & -0.1 & 0.415 & -0.238 & 0.143 & -0.022 & 0.179 & 0.057 & 0.071 & 0.054 \\
\hline 2012 & -0.152 & 0.005 & 0.113 & 0.13 & -0.022 & 0.135 & 0.06 & 0.05 & 0.026 \\
\hline
\end{tabular}

Table3. Sample data of alarm indexes in unsalable cabbage of Shandong

\begin{tabular}{|l|c|cccccccccccc|c|}
\hline Year & 2000 & 2001 & 2002 & 2003 & 2004 & 2005 & 2006 & 2007 & 2008 & 20092010 & 2011 & 2012 \\
\hline $\begin{array}{l}\text { Price } \\
(\%)\end{array}$ & volatility & -9.4 & 33.5 & -14.2 & 45.5 & -2 & 20.8 & -5.334 .21 & -10.78 .36 & 41.530 .046 & -10.82 \\
\hline Expectation & -0.5 & 1 & -1 & 1 & 0 & 1 & -0.5 & 1 & -1 & 0.5 & 1 & 0 & -1 \\
\hline
\end{tabular}

According to previously identified Shandong cabbage unmarketable warningindicators, the number of hidden layer nodes is $(14+1-1) / 2+a$, if we take $a=3$, then the number of nodes in the hidden layer is 10. When using Matlab software to trainthe early-warning model of BP neural network, wechoose the index data from 2000 to 2009 in Table 3 as the training sample, set up the learning rate of 0.05 , the training error of 0.00015.The results meet the requirements after 2350training iterations; the corresponding results are shown in table 4.

Table4 The training results of Shandong cabbage unmarketable warning model

\begin{tabular}{|l|lccccccr|}
\hline Year & 2000 & 2001 & 2002 & 2003 & 2004 & 2005 & 2006 & 2007 \\
& 2008 & 2009 & & & & & & \\
\hline Expectation & -0.5 & 1 & -1 & 1 & 0 & 1 & 0.5 & 1 \\
& -1 & 0.5 & & & & & & \\
\hline Output & -0.5020 & 0.9659 & -0.9885 & 0.9932 & -0.003 & 0.9932 & 0.5023 & 0.9984 \\
& -0.9892 & 0.4998 & & & & & & \\
\hline
\end{tabular}

From table 4 we can see that the output is very close to our expectations, it shows that the early-warning model we have established meets the requirements.

In order to validate our early warning model, we used sample data of premonition indexes of 2010-2012, the results are shown in Table 5. 
Seen from Table 5, the output and the unsalable degree we expect is very close, the warning model we established ofChinese cabbage unsalable meets the requirements.

Table 5Validation results of Shandong
\begin{tabular}{|l|l|l|l|}
\hline Year & 2010 & 2011 & 2012 \\
\hline Expectation & 1 & 0 & -1 \\
\hline Output & 0.9978 & 0.0017 & -0.9783 \\
\hline
\end{tabular}

\section{Conclusion}

We successful build the early warning model of Shandong cabbage unsalable by training and verifying a large number of indicators and historical data, and further illustrates the early warning model of vegetable unmarketable based on BP neural network is feasible. With this method we can build other agricultural products unmarketable warning model such as vegetables, fruits or meat. Construction and application of early warning model of vegetable unsalable can help farmers forecast the direction of vegetable market in the future. If the forecast will be unsalable phenomenon, some measures can be taken in advance, for example, we can reduce the unsalable vegetables production to produce other best-selling agricultural products, extend vegetable market and do vegetable deep processing, hereby reduce losses brought unmarketable vegetables.

\section{Acknowledgement}

This work was supported by the National Natural Science Foundation of China (71372120); the National Science Foundation for Young Scientists of China (41101158); Liaoning Provincial Natural Science Foundation (2013020006);2014 Liaoning BaiQianWan Talents Program (Third Category); Liaoning Social Science Planning Fund Plan (L14CJY041); 2014 Dalian Science and technology project from Dalian Municipal Science and Technology Bureau(2014D11ZC117);Liaoning Provincial Education Department (W2012246); National Science Foundation for Post-doctoral Scientists of China (2014M550084); Scientific Research Foundation for the Returned Overseas Chinese Scholars, State Education Ministry; Dalian Jinzhou New District Science and technology project (2013-2kx2-001)..

\section{References}

[1]Su Xiaoyan, Zhang Huijie, Li Zhiqiang, etal, China food security early warning system based on multiple factors Information Fusion. Nuclear Science and Techniques, Vol.5(2012) No,27.

[2]Xia Tian,ZhouYong,Regional food security early warning research. Journal ofHuazhong Normal University( Humanities and Social Sciences), Vol.1(2012) No,51.

[3]FengYonghui,Construction of early warning system on live pig market monitoring .Chinese Academy of Agricultural Sciences, 2012.

[4]Zhao Ruiying, Yang Xuecheng,Establishment and application of agricultural prices risk warning model. Research of Agricultural Modernization, Vol.2(2008).

[5] Li Chongguang, Li Youzhu, Li Gucheng, The research of vegetable prices early warning system in our country.Journal of Agrotechnical Economics, Vol.7(2014).

[6]Tang Jiangqiao, Lei Na, The building of price volatility warning indicator system of livestock. Management Journal, Vol.6(2012) No,25. 
[7] Yi Zezhong,GaoYang,GuoShiyin,etal, Risk evaluation and empirical analysis of China's pig market price. Issues in Agricultural Economy, Vol.4(2012) No,13.

[8]Li Dongguang, The marketable agricultural issues based on Logistics.TheAgriculturalEconomy,Vol.7(2012)

[9]Wei Junying, Zhu Xinkai, The empirical study of relationship between food prices and inflation. China's agricultural resources and gegional,Vol.4(2013)

[10]Zhao Ruiying,Astudy on early-warning and management of agricultural productmarketrisks.Shandong Agricultural University,2006. 